\title{
“Clickable” Polyglycolides: Tunable Synthons for Thermoresponsive, Degradable Polymers
}

\author{
Xuwei Jiang, Erin B. Vogel Milton R. Smith, III,* Gregory L. Baker*
}

Department of Chemistry, Michigan State University, East Lansing, MI, 48824

smithmil@msu.edu, bakerg@msu.edu

Supporting Information

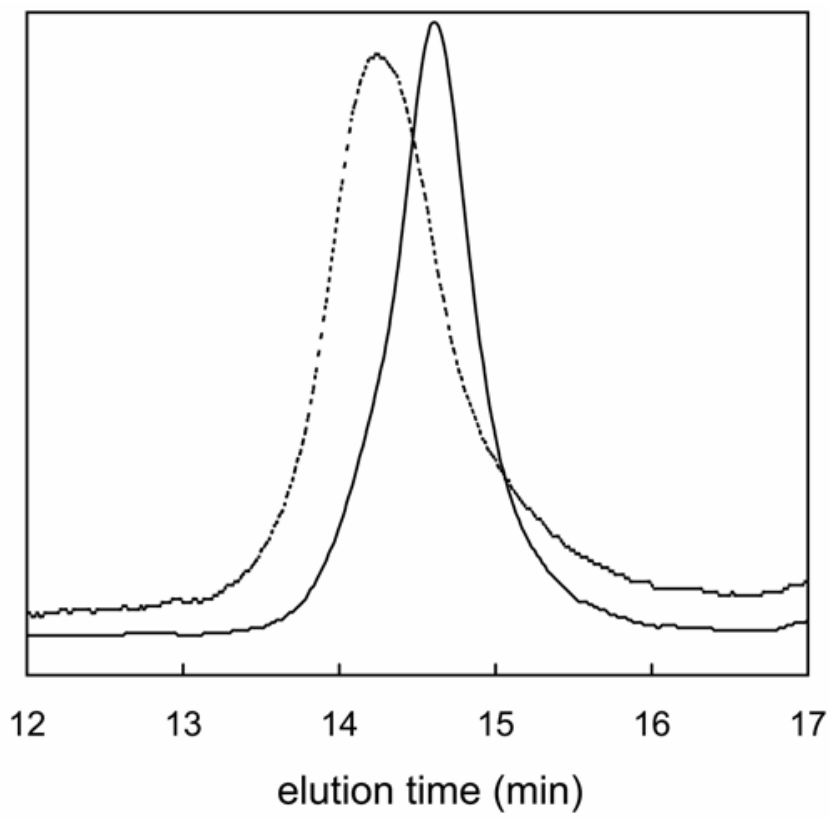

Figure S1. GPC traces of the PPGL macroinitiator (solid line), and PPGL-blockpolylactide. (broken line). The polymers were analyzed in THF at $35{ }^{\circ} \mathrm{C}$, at a 1 $\mathrm{mL} / \mathrm{min}$ flow rate. 


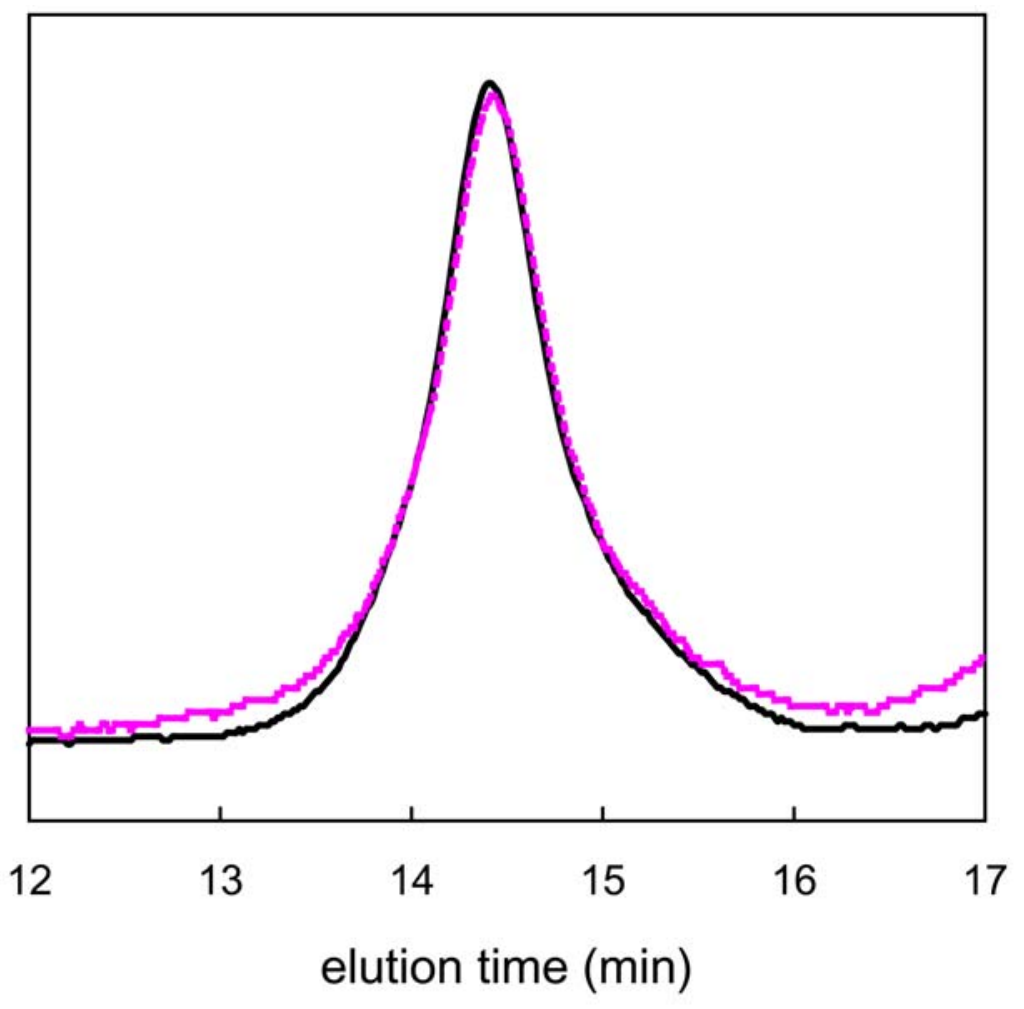

Figure S2. GPC traces from a control reaction where PPGL was exposed to "click" conditions, but without added azide. (black line: PPGL before the reaction; pink line: PPGL after the reaction. 